that patient's confidence and inform the DVLC, if the doctor believes that an individual patient's mental disorder is likely to make his or her driving a source of danger to the public. It is recommended that doctors contemplating such a step should consult with their defence organisation before so doing.

\section{References}

Brttish Medical association \& Royal Pharmaceutical SOCIETY OF GREAT BRTtaIN (1993) British National Formulary. Number 25. London: Pharmaceutical Press.

DRIVER \& Vehicle LiCensing AGENCY (1993) At a Glance Guide to the Current Medical Standards of Fitness to Drlue. Swansea: DVLA.

HINDMARCH, L. (1988) A pharmacological profile of fluoxetine and other antidepressants on aspects of skilled per- formance and care handling ability. British Journal of Psychiatry. 163 (suppl. 3). 99-104.

RAFFLE. A. (Ed) (1985) Medical Aspects of Futness to Drive. London: The Medical Commission on Accident Prevention.

RoYal College of PSYchiatrists (1981) Psychiatric Disorders Contra-indicated for Drivers of Heavy Goods Vehicles (HGVs) and Public Service Vehicles (PSVs). London: Royal College of Psychiatrists.

SILVERSTONE, T. (1988) The influence of psychiatric disease and its treatment on driving performance. International Clinical Psychopharmacology, 3 (suppl. 1) 59-66.

Andrew Lawrie, Registrar; and *Steven Milne, Senior Registrar, St Nicholas Hospital, Jubilee Road, Gosforth, Newcastle upon Tyne NE3 3XT

*Correspondence

\title{
Do patients who have been on 'sections' get refused visas?
}

\author{
Danny Allen and Karen Allen
}

\begin{abstract}
A reason sometimes given for not applying a section of the Mental Health Act 1983 to patients for the first time is that this may stigmatise them in some way. A practical example of stigmatisation is that patients who have previously been 'sectioned' may be refused tourist or immigration visas to other countries. Since no information on this subject is avaliable in the psychiatric Iiferature this paper aftempts to clarity the policy of diplomatic missions in the UK in relation to visa applicants who report a history of mental iliness and compulsory hosplital treatment.
\end{abstract}

\section{The study}

A questionnaire was sent to the visa departments of 110 embassies, consultates and high commissions in London, representing all the diplomatic establishments which could be accessed through the Business and Services volume of the London Telephone Directory. The questionnaire addressed four areas: applicants for visitors' visas who had been detained under section 2 or section 3 and those detained under these two sections who had applied for immigration visas. The respondents were asked to ring one of five possible answers for each category and were also given an opportunity for each category to give an alternative answer of their own.

The five choices were: would you refuse a visa on the grounds of the 'section' alone, on the grounds of mental ill health alone, request further information/make further inquiries, discount this information entirely for that class of visa, or ignore it if the event occurred some time ago (how many years?). Due to a poor initial response a reminder was malled three months later.

\section{Findings}

After two mailings, 77 replies were received from 110 questionnaires. Sixty-five $(59 \%$ of the total sample) answered the questionnaire, the others sending inappropriate literature or stating that they would have to send the questionnaire to their parent country.

No differences were recorded on any questionnaire between sections 2 and 3, therefore these have been dealt with together.

Thirty-four countries (52\%) reported that they would discount any record of hospital admission under a section of the Mental Health Act, 1983 
for visitors' visas and 27 (42\%) would request further information or make further inquiries, or both, for this category of visa. Nepal would refuse a visitor's visa on the grounds of these sections, and Uganda. The Philippines, Lesotho, Vietnam and Gambia would refuse it on the grounds of mental illness alone. Bolivia and Sri Lanka said that they had received no such applications and hence were unable to state a position on the subject. Liberia would discount information relating to mental illness after a period of two years had elapsed and Malaysia would have to refer to Immigration Headquarters for a decision.

Twenty-two countries (34\%) said that they would discount a record of detention under a section of the Mental Health Act, 1983 for immigration visas and $36(55 \%)$ would request further information or make further inquiries, or both, for this category of visa. Saudi Arabia and Vietnam would refuse an immigration visa on the grounds of these sections and Uganda. The Philippines and Gambia would refuse it on the grounds of mental illness alone. Four embassies said that they were not authorised to give this information and Nepal and Liberia said that this was not applicable to their country.

Although we did not want to single out countries, we are aware that the policy of the USA may be of interest to readers. The embassy of the USA reported that they would request further information or make further inquiries, or both, in the case of both visitors' and immigration visas.

\section{Conclusions}

Despite the anecdotal evidence that this was a problem, we could find no research which had been done in this area at all.
From our research it is clear that in the case of both visitors' and immigration visas the norm is for embassies to discount any information on previous compulsory psychiatric admissions (in many cases because there is no legislation covering this area) or to request further information from the applicant or from other sources. Hence it is clear that with the exception of Nepal for a visitor's visa and Saudi Arabia and Vietnam for immigration visas there is no question of either a section 2 or a section 3 on its own being the reason a visa is refused.

Many countries sent back more detalled information and it was clear that some have no reference to mental health issues in their legislature. Of those countries that have regulations regarding the mental health of aspiring immigrants, several implied that immigration visas would be refused if the severity of the disorder was sufficient to disrupt the public or interfere with the individual's capacity to work. Hence previous mental illness, whether requiring a section or not, would not be a valid reason, on its own, to refuse a visa, whereas current illness, even without a section, might lead to a refusal.

\section{Acknowledgement}

We would like to thank the staff of the diplomatic missions who answered our questions for their co-operation.

Danny Allen, Senior Registrar, Blackberry Hill Hospital, Manor Road, Flshponds, Bristol BS16 2EW; and Karen Allen, Psychology Student, Open University, Multon Keynes MK7 6AP 